\section{Estimulação visual na criança: a intervenção dos profissionais de terapia ocupacional}

É com muita satisfação que observo o crescimento da assistência à criança visualmente deficiente nos vários cantos deste país. Outrora, observava-se apenas uns grupos de profissionais da área da reabilitação espalhados pelo eixo São Paulo - Rio de Janeiro - Minas Gerais.

Ao ler os artigos publicados na edição de agosto dos Arquivos Brasileiros de Oftalmologia, chamou-me a atenção a publicação do estudo realizado pela Fundação Altino Ventura, em Recife, sobre desempenho funcional de crianças com deficiência visual, atendidas no Departamento de Estimulação Visual da Fundação Altino Ventura ${ }^{(1)}$. Além de ser um grupo de estimada competência, são profissionais que ampliam sua assistência com outros profissionais da área da saúde, que, com certeza só fazem crescer aqueles a quem estão assistindo.

A inclusão da Terapia Ocupacional na equipe clínica da referida Fundação, denota o interesse pelo crescimento científico, além de apresentar aos leitores dos Arquivos o belo trabalho que vem sendo realizado no Nordeste do Brasil. Atualmente, na assistência à criança visualmente deficiente, podemos conhecer trabalhos realizados por estes profissionais em Recife, Salvador e Fortaleza.

$\mathrm{O}$ terapeuta ocupacional quando se dedica à assistência ao deficiente visual abrange na sua intervenção conhecimentos sobre desenvolvimento visual e infantil. Montilha et al., afirmam que a intervenção terapêutica ocupacional após avaliação oftalmológica contribui para a compreensão pelos pais, das possibilidades de desenvolvimento dos seus filhos, apesar da dificuldade apresentada por eles ${ }^{(2)}$.

O trabalho desenvolvido por esta categoria profissional, aos visualmente incapacitados em Recife, tem crescido de maneira a apresentar dados concretos sobre a importância e necessidade deste tipo de intervenção para esta clientela. É importante que se comente sobre a necessidade de ampliação das equipes clínicas para assistência visual, visto que o desenvolvimento do conhecimento científico aponta para a atuação de profissionais das áreas afins.

Meu desejo é que outros estudos, com esta finalidade possam ser registrados e que os Arquivos Brasileiros de Oftalmologia possam continuar a ser o caminho para a divulgação destes trabalhos.

\section{Referências:}

1. Malta J, Endriss D, Rachel S, Moura T, Ventura L. Desempenho funcional com deficiência visual, atendidas no Departamento de Estimulação Visual da Fundação Altino Ventura. Arq Bras Oftalmol. 2006;69(4):571-4.

2. Montilha RCI de, Nobre MIRS, Gagliardo HGR. Atuação terapêutico-ocupacional junto a pacientes com transtornos da visão. In: De Carlo MMR do P, Luzo MC de M. Terapia ocupacional: reabilitação física e contextos hospitalares. São Paulo: Roca; 2004. p.276-91.

Raquel Costa Albuquerque

Docente do Curso de Terapia Ocupacional e Doutoranda em Saúde Materno Infantil da Universidade Federal de Pernambuco - UFPE - Recife (PE) - Brasil.
Caro Editor,

Escrevo esta carta para comentar o relato de caso publicado por Farias et al. ${ }^{(1)}$. Primeiramente, elogio os autores pelo artigo e por estimularem a discussão sobre o aperfeiçoamento das rotinas para o rastreio de cirurgias refrativas nos doadores de córneas.

No artigo publicado ${ }^{(1)}$, os autores mencionam os resultados preliminares de Terry e Ousley ${ }^{(2)}$ sobre o uso do Orbscan para o rastreamento de cirurgias refrativas em doadores de córneas. Além daquele estudo, Ousley e Terry ${ }^{(3)}$ avaliaram, posteriormente, as diferenças regionais dos dados paquimétricos e dos mapas de curvatura, gerados pelo Orbscan, conseguindo detectar $40 \%$ das córneas previamente submetidas à cirurgia refrativa, ao analisar a paquimetria isoladamente. Empregando apenas os mapas de curvatura, o índice de acerto foi o mesmo. A associação dos dois métodos, por sua vez, aumentou o índice de acerto para $70 \%$, melhorando a sensibilidade do método. Ainda baseados no princípio das diferenças regionais, os mesmos autores avaliaram o uso de um topógrafo portátil, obtendo resultados animadores, ampliando as possibilidades desta tecnologia como método de rastreio ${ }^{(4)}$.

Outra técnica sugerida consiste no emprego da tomografia de coerência óptica (OCT). Utilizando este equipamento, Priglinger et al., detectaram a interface entre o flap corneano e o estroma residual em todas as córneas examinadas, em diferentes profundidades de ablação ${ }^{(5)}$. Ulteriormente, o mesmo grupo confirmou a capacidade da OCT em detectar alterações induzidas pelo LASIK na avaliação postmortem imediata e durante o período de preservação ${ }^{(6)}$.

Por último cabe mencionar um estudo ${ }^{(7)}$ que comparou a biomicroscopia (BM) e a microscopia especular (ME) como métodos de rastreio, avaliando 26 córneas com LASIK prévio e 26 controles. Com a BM foi possível encontrar o flap em $84,6 \%$ das córneas com LASIK prévio, enquanto a ME identificou corretamente $88 \%$ das córneas ( $\mathrm{p}<0,001$ em relação aos controles). Assim, a associação da ME com a BM parece ser uma opção para ajudar na detecção de córneas previamente submetidas ao LASIK.

\section{Referências:}

1. Farias RJM, Parolim A, Sousa LB. Transplante de córnea com uso inadvertido de córnea de doador previamente submetido à cirurgia refrativa - relato de caso. Arq Bras Oftalmol. 2005;68(2):266-9.

2. Terry MA, Ousley PJ. New screening methods for donor eye-bank eyes. Cornea 1999;18(4):430-46.

3. Ousley PJ, Terry MA. Objective screening methods for prior refractive surgery in donor tissue. Cornea. 2002;21(2):181-8.

4. Ousley PJ, Terry MA. Use of a portable topography machine for screening donor tissue for prior refractive surgery. Cornea. 2002;21(8):745-50.

5. Priglinger SG, Neubauer AS, May CA, Alge CS, Wolf AH, Mueller A, et al. Optical coherence tomography for the detection of laser in situ keratomileusis in donor corneas. Cornea. 2003;22(1):46-50.

6. Wolf AH, Neubauer AS, Priglinger SG, Kampik A, Welge-Luessen UC. Detection of laser in situ keratomileusis in a postmortem eye using optical coherence tomography. J Cataract Refract Surg. 2004;30(2):491-5.

7. Mootha VV, Dawson D, Kumar A, Gleiser J, Qualls C, Albert DM. Slitlamp, specular, and light microscopic findings of human donor corneas after laserassisted in situ keratomileusis. Arch Ophthalmol. 2004;122(5):686-92.

\section{Luciano P. Bellini}

Médico Oftalmologista. Fellow em Córnea e Doenças Externas no Hospital de Clínicas de Porto Alegre - HCPA - Porto Alegre (RS) - Brasil. Pós-Graduando nível Doutorado pela Universidade Federal do Rio Grande do Sul - UFRGS Porto Alegre (RS) - Brasil.

Endereço para correspondência: Av. Ipiranga, 3377 - Apto. 903 - Porto Alegre (RS) CEP 90610-001. E-mail: lucianopbellini@yahoo.com.br 